\title{
7. Moral Development and Ethical Decision-Making
}

\author{
Judi Sture
}

\begin{abstract}
A variety of approaches aimed at mitigating the intermittent friction between science and society and the risks of malign use of modern scientific advances has been defined: ethics, ${ }^{1}$ the responsible conduct of science, ${ }^{2}$ self-governance by scientists, ${ }^{3}$ and top-down initiatives from policymakers and other authorities. ${ }^{4}$ These approaches have allowed for a number of perspectives on the challenges that biosecurity poses to society and biotechnology today, but none has considered the pre-existing values of stakeholders as they interact with these challenges.
\end{abstract}

I would suggest that scrutinising the cultural pressures, forces and processes that influence the development of the values that individuals bring to their scientific work and policy views will shed further light on possibilities for engagement with dual use. The lack of attention to this so far is possibly due to the apparent lack of recognition of the role played by what may be called 'moral development' in ethical decision-making processes. We need to ask whether the private and the public value sets held by individuals clash; is it possible to hold multiple value sets in our private and professional lives and still manage to operate effectively in one or both spheres? These are some of the questions that need attention in approaching the potential challenges involved in deciding what is good, bad, right or wrong in the context of scientific work and its effects both inside and beyond the laboratory door.

The processes by which we learn and adopt 'moral' stances have been recognised and studied for more than 100 years. An influential work on what he termed 'folkways's by W. G. Sumner, professor of political and social science at Yale University in the late nineteenth and early twentieth centuries, described and interpreted the development of both 'individual habits' and 'group customs' as they develop into morality-mediated usage in specific groups. He believed that moral values and their associated behaviours achieve the status of 'unwritten

\footnotetext{
1 Selgelid, M. J. 2010, 'Ethics engagement of the dual use dilemma: progress and potential', in B. Rappert (ed.), Education and Ethics in the Life Sciences: Strengthening the Prohibition of Biological Weapons, ANU E Press, Canberra, pp. 23-34, <http://epress.anu.edu.au/education_ethics/pdf/ch0l.pdf >.

2 National Research Council/Institute of Medicine 2006, Globalization, Biosecurity and the Future of the Life Science, The National Academies Press, Washington, DC.

3 Royal Netherlands Academy of Arts and Sciences 2008, A Code of Conduct for Biosecurity: Report by the Biosecurity Working Group, KNAW, Amsterdam.

4 For example, Friedman, D. 2010, 'Israel', in Rappert, op. cit., pp. 23-34.

5 Sumner, W. G. 1906, Folkways: A Study of the Sociological Importance of Usages, Manners, Customs, Mores, and Morals, Ginn \& Co., Boston, <www.gutenberg.org $>$.
} 
laws' for the individual and the group because 'popular usages and traditions, when they include a judgment that they are conducive to societal welfare ... exert a coercion on the individual to conform to them, although they are not coordinated by any authority'. ${ }^{6}$ I would argue that this is a relatively accurate description of the position of most scientists and science stakeholders today in the early years of the twenty-first century.

It is important that recognition of the role of pre-existing cultural folkways (national/ethnic, economic, religious, social and technological values and so on) and within these, domestic (familial) folkways or value sets, is factored in to any consideration of how individuals reach a state of moral and ethical maturity in their private and professional lives. This is particularly important in science, where the rapid speed of advance typically outstrips the development of appropriate ethical responses needed to deal with it and in which it is typically supposed that all practitioners share a common set of professional values and perspectives by virtue of their identity as scientists.

This chapter looks at the issues of moral development and ethical decisionmaking in terms of the publicly stated group value sets and individual, privately held value sets. Later in the chapter, I describe the case of a 'conflicted scientist' as he tries to make sense of a number of professional/personal value conflicts that face him in his daily work life. This unfortunate individual faces a set of daily challenges that create an uncomfortable dissonance in him; he needs to find a way in which to move forward without disadvantaging himself. Such ways forward cannot be identified unless we have a better understanding of the origins of the dissonance. By focusing on biological, psychological and anthropological research into the development of value systems, within the context of cultural identity, it is possible to highlight possible mechanisms that may usefully be explored in further research.

\section{Terminology}

Many authors use the term 'morals' to refer to ethical practice, standards or beliefs; indeed it is common to find that the words 'morals' and 'ethics' are used interchangeably. The very fact that there is this lack of clarity and consensus in this vocabulary indicates a lack of understanding of the potential differences between private and public values held by both individuals and groups. Because this chapter focuses on the potential variance between private and public value sets, I have chosen to be specific in the way I use these terms. For the purposes of this chapter, the term morals will be used to refer to the attitudes and values 
learned in childhood, pre-professional and private life, and the term ethics to refer to the attitudes and standards learned and required in the context of professional life.

The word 'moral(s)' tends to be heavily laden with culture-specific values and especially religious meaning, both of which are highly influential in forming our early values and views. These values may belong to a value set separate to that held professionally (although religious values may also direct ethical values). Furthermore, many people think of 'morals' as the attitudes they learned from their personal and family lives, with 'ethics' being something outside the domestic sphere: 'a morality for the private sphere that is personal and subjective, and a morality for the public sphere that is impersonal and objective. $^{7}$

The English word 'mores' - meaning values, norms and, occasionally, virtues is derived from the Latin plural noun mores. 'Mores' refers to the traditions and customs practised by specific groups, which relate directly to the subject of this chapter. These traditions and customs are derived from accepted behaviours and practices in a group rather than from actual laws, and consist of a shared understanding of the manners and conduct that are acceptable to and expected by the group. In short, either one conforms to the traditions and customs of the group or one cannot function effectively as a full member. Indeed, an individual whose values clash with the predominant values of the group may find that s/ he is not welcome in it at all.

'Folkways', according to Sumner, 'are habits of the individual and customs of the society which arise from efforts to satisfy needs'. These folkways can be understood as informal mores and, while not generally enforced in any way, they tend to be perpetuated by members of the group emulating the behaviours and attitudes of older or more established members. Once folkways are established, they become, essentially, a value set that is shared by members of the group and is maintained by group consent rather than by formal governance. Clearly this process has implications in the biosecurity context when we are seeking to develop, in effect, a new norm of biosecurity to which all scientists and science stakeholders can subscribe.

In this chapter, the term 'culture' refers to the 'culture of origin' of the individual (as in the ethnic sense), as well as to nationality and to religious, economic, technological and linguistic groupings to which the individual may belong. All of these dimensions impact on one another, having differing degrees of influence depending on the context in which the individual is acting at any one time. One of the outputs of such cultural influence is a value set, or group of value sets.

7 Catchpoole, V. M. 2001, 'A sociobiological, psychosocial and sociocultural approach to ethics education', PhD, Centre for the Study of Ethics, School of Humanities, Queensland University of Technology, Brisbane, p. 274. 
These may also be defined as beliefs, attitudes and perspectives on the world. Clearly, these in turn impact on actions and behaviour patterns. Clashes occur when an individual is faced with some conflict between the influences of one or more cultural value sets in a given situation. Which value set should have precedence?

'Ethics' may be defined as (potentially) universal standards and commitments that support justice, care, welfare and rights; ${ }^{8}$ among other definitions, they may also be defined as a 'principled sensitivity to the rights of others' ${ }^{9}$ The irony here is, of course, that most people tend to believe that their own 'moral' (private and/or family derived) standards are also defined in the same way. Variations in these have a role in defining scientists' and policymakers' ethical standards and norms and must be recognised as key variables in any debate about what needs to be done to prevent the hostile use of the life sciences. Nevertheless, bearing in mind that cultural variations exist, it is probably reasonable to agree that any desired socially responsible 'ethical' approach involves 'the development of adequate ... commitments that inform actions' ${ }^{10}$ and that this includes 'an understanding of what is beyond self-interest, and how we may justify that to reasonable people and put it into practice'. ${ }^{11}$ Even so, these aspirations, while striving to be comprehensive and culture neutral, still incorporate approaches that may not be prioritised by all cultures and therein lies part of the difficulty in seeking a common set of values or norms. Everyone thinks that their existing moral outlook is 'commonsense', and that their professional ethical values are also 'commonsense'. It is in this balancing act between the variation in moral and ethical values as defined by diverse cultural backgrounds that we need to find a way forward that allows individuals and groups to engage equally and openly in the context of biosecurity as it challenges the needs of science in the way it meets the needs of society.

\section{Private morals and public ethics: Cultural aspects of moral development}

Given that cultural origins vary significantly, while providing a fundamental platform of values from which each individual views the world, it follows that everyone has at least one value set that influences the ways in which they see, understand (or believe they do) and treat other people. Most people have multiple value sets, and apply them variously in the different contexts of their lives - for example, we may adhere to one value set in the family or domestic

8 Laupa, M. and Turiel, E. 1995, 'Social domain theory', in W. M. Kurtines and J. L. Gewirtz (eds), Moral Development: An Introduction, Allyn \& Bacon, Boston, pp. 455-73.

9 Gilbert, N. 2001, Researching Social Life, Sage, London, p. 45.

10 Catchpoole, op. cit., p. 7.

11 Singer, P. 1993, How Are We to Live? Ethics in An Age of Self-Interest, Text, Melbourne. 
sphere, but another in the work context; we may employ yet more value sets in our relations with people we do not like, or with people we need, such as our bank manager or our doctor.

\section{How we learn about morality: Mechanisms of development}

This section introduces two processes of moral learning, which may be applied in understanding the development of ethical thinking in the context of professional science.

The development of a moral or ethical perspective presupposes the biological capacity to do so. Growing up, we process moral learning as part of our social heritage through our ability to symbolically represent the moral to ourselves, which involves a relational aspect between ourselves and others:

[C]ulture serves to complement the process [of learning morality] in important ways. Rather, we are led to moral experience and insight. Real morality can't be forced on people, nor can they be fooled into having it, nor do they just act on their 'moral instincts'. Real morality does not simply bubble up from beneath, nor is it imposed from the outside. In each one of us, it must be discovered anew. The discovery process may require great mental and emotional effort and may bloom only in the right climate, but human beings see morality, recognize it, regardless of what it is that they want or need or love or hate or feel compelled to do. ${ }^{12}$

We learn what is good and what is bad primarily in relation to ourselves as individuals, but also, through social development, what is good and bad for 'the others'. These 'others' will initially be the close 'others' of family and friends. Later, this can develop also into a sense of shared experience, and care or empathy with the distant other: the outsider or even the enemy, the one who is not a close other. Perhaps this conscious decision to have empathy for the enemy or the outsider, the different one, is a measure of our ethical maturity.

Edward Wilson ${ }^{13}$ suggested that genetics and evolutionary processes shape the human mind at least as much as culture, that a predisposition to religious belief is genetically driven in humans and that acting altruistically through religious belief can confer survival advantages to those willing to change their views. Wilson also described the dark side of our predisposition to tribal affiliationsxenophobia - and suggested there is a need to 'globalise the tribe' ${ }^{14}$ In terms of the debate on dual use and biosecurity, it may be useful to consider the relative

12 Goodenough, U. and Deacon, T. W. 2004, 'From biology to consciousness to morality', Tradition \& Discovery: The Polanyi Society Periodical, vol. 30, part 3, pp. 6-20.

13 Wilson, E. O. 1978, On Human Nature, Harvard University Press, Cambridge, Mass.

14 Wilson, E. O. 1998, Consilience: The Unity of Knowledge, Alfred A. Knopf, New York, p. 269. 
positions of those defending the practice of research from security-inspired interventions and those urging a change in attitude to the nature of scientific freedom. These may be considered as belonging, at least in the eyes of some, to different 'tribes' and thus be subject to 'intertribal' conflict.

In order to consider any change of allegiance (in our context, in terms of changing what $\mathrm{s} / \mathrm{he}$ thinks is 'ethical'), an individual or group must be able to reflect on and evaluate a range of cultural factors that pertain to the situation, and then make an informed decision as to whether change of allegiance is the right choice. The change may incur a short or a long-term cost, but the ability to consider the change and the costs is part of a moral capacity, leading to the application of moral agency. Essentially, the individual is faced with the choice of allegiance or reprioritisation of values.

Griffiths ${ }^{15}$ considered that emotions play a key part in our moral response system, and therefore in our capacity for moral agency, while Izard and colleagues suggested that emotions have an adaptive role in equipping individuals to act appropriately in order to survive. ${ }^{16}$ We can already see this in action in our prioritisation and negotiation of values between the private morals and public ethics in any given situation.

Wilson's views have been criticised by the evolutionary biologists Stephen Jay Gould and Richard Lewontin, who oppose ideas of genetic determinism, and the anthropologist Marshall Sahlins, who holds to the view that cultural factors are a powerful driver of people's behaviours, distinct from genetic influences. Other researchers, however, have also supported a biological mechanism in the development of values. The evolutionary biologist Robert Trivers ${ }^{17}$ suggested that reciprocal altruism (all parties helping each other in order to survive) is an evolutionary predisposition that offers the best chance of survival of the individual and the species. Moore, ${ }^{18}$ however, has pointed out that it is not always easy to distinguish between altruism and selfish acts disguised as altruism. Richard Dawkins ${ }^{19}$ suggests that some biological determinants are non-altruistic and reflect a predisposition to look after oneself, rather than considering possible self-sacrifice for the good of others. Williamson ${ }^{20}$ argues that the human concepts of shame and guilt function in evolutionary terms as restraints on social behaviour, and points out that human self-interest is an

15 Griffiths, P. E. 1998, What the Emotions Really Are: The Problem of Psychological Categories, University of Chicago Press, Chicago.

16 Izard, C. E. 1984, 'Emotion-cognition relationships and human development', in C. Izard, J. Kagan and R. B. Zajonc (eds), Emotion, Cognition and Behavior, Cambridge University Press, Cambridge, pp. 17-37.

17 Trivers, R. 1971, 'The evolution of reciprocal altruism', Quarterly Review of Biology, vol. 46, pp. 35-57.

18 Moore, J. 1984, 'The evolution of reciprocal sharing', Ethology and Sociobiology, vol. 5, pp. 5-14.

19 Dawkins, R. 1976, The Selfish Gene, Oxford University Press, Oxford.

20 Williamson, D. 1998, 'Mixed feelings', The Australian Review of Books, June, pp. 14-15, cited in Catchpoole, op. cit., p. 60. 
obvious factor in survival: those of our ancestors who looked after their own interests survived to reproduce themselves, and those who did not, failed to do so.

Work by Krebs and Janicki ${ }^{21}$ indicated that the evolutionary development of norms, or memes as Dawkins may refer to them (which may be defined as culturally transmitted units of data such as ideas, habits and so on), has resulted in four identifiable ways in which people operate ethically

1. they try to get others to invoke the norms that they themselves hold

2. they try to tailor their norms to others so as to enhance their persuasive impact

3. recipients tend to adapt to the norms that are most advantageous to them

4. people in different sorts of relationships will preach different sorts of norms.

These 'operating mechanisms' are, according to Krebs and Janicki, biologically determined in that they are evolutionary adaptations to ensure survival. Whether these mechanisms are truly biological or are solely culturally determined artefacts is open to debate.

The development of reciprocity, empathy and other relationship-related characteristics may be considered as part of a psycho-cultural mechanism of learning morality and ethics. Our capacity to consider the needs of others is enhanced by our cultural interactions with other people at a psychological level. Most people learn how to make and sustain friendships, work relationships and marriage relationships based on cultural concepts such as respect, interdependence, empathy, cooperation and negotiation, amongst others. All of these are partial foundations of a moral and ethical perspective, even though they vary in how they are prioritised and expressed culturally.

Research suggests that humans can exhibit empathy (the capacity to intellectually understand how another person feels) from an early age, which is potentially open to development by other cultural factors. Work by a number of psychologists has shown that even very young children have the capacity for empathy. ${ }^{22}$ This runs contrary to earlier thought by Piaget, ${ }^{23}$ who believed that very young children were essentially egocentric and unable to perceive the world from the perspective of others. Hoffman devised a set of levels in the development of empathy encompassing the first 12 years of life. ${ }^{24}$

\footnotetext{
21 Krebs, D. L. and Janicki, M. 2004, 'Biological foundations of moral norms', in M. Schaller and C. Crandall (eds), Psychological Foundations of Culture, Lawrence Erlbaum Associates, Mahwah, NJ, pp. 125-48.

22 For example, Hoffman, M. L. 1988, 'Moral development', in M. H. Bornstein and M. E. Lamb (eds), Social, Emotional and Personality Development. Part III of Developmental Psychology: An Advanced Textbook, Lawrence Erlbaum Associates, Hove, UK, pp. 497-548; Zahn-Waxler, C., Radke-Yarrow, M. and Wagner, E. 1992, 'Development of concern for others', Developmental Psychology, vol. 28, part 1, pp. 126-36.

23 Piaget, J. 1932, The Moral Judgment of the Child, Kegan Paul, London.

24 Hoffman, M. L. 1988, 'Moral development', in Bornstein and Lamb, op. cit.
} 
A major player in the development of moral theory learning was Kohlberg. ${ }^{25}$ He developed a six-stage model of moral development, with successive stages being more able to affect moral reasoning. His model focuses particularly on the concept of justice and he believed that this development continues throughout adult life. He further developed his model to accommodate 'soft' developmentallevel changes in adults over the age of about thirty years, and acknowledged that his stages do not provide a complete description of adult development from stage four onwards ${ }^{26}$ (see Table 7.1). It must be noted, however, that Kohlberg's stages refer not to specific beliefs but to underlying modes of reasoning, ${ }^{27}$ and as such, there is no guarantee that an individual will reach the highest level of reasoning. Also, it should be noted that Kohlberg's work focuses on moral thought, not moral action, and we can probably all accept that the two do not always go together.

\section{Table 7.1 Kohlberg's Six-Stage Model of Moral Reasoning}

\begin{tabular}{|c|c|}
\hline \multirow{2}{*}{$\begin{array}{l}\text { Level 1: } \\
\text { Pre- } \\
\text { conventional } \\
\text { morality }\end{array}$} & $\begin{array}{l}\text { Stage 1: Punishment-obedience orientation (avoiding punishment for doing } \\
\text { 'wrong', but only because it is good for you) }\end{array}$ \\
\hline & $\begin{array}{l}\text { Stage 2: Instrumental relativist orientation (how will this decision/action be } \\
\text { good for me and my needs?) }\end{array}$ \\
\hline \multirow{2}{*}{$\begin{array}{l}\text { Level 2: } \\
\text { Conventional } \\
\text { morality }\end{array}$} & $\begin{array}{l}\text { Stage 3: Interpersonal concordance (being 'good' to please other people } \\
\text { because that is the 'right' thing to do) }\end{array}$ \\
\hline & $\begin{array}{l}\text { Stage 4: Law and order orientation (abiding by laws for the good of } \\
\text { society, not just for the resulting benefits to yourself) }\end{array}$ \\
\hline \multirow[t]{2}{*}{$\begin{array}{l}\text { Level 3: } \\
\text { Post- } \\
\text { conventional } \\
\text { morality }\end{array}$} & $\begin{array}{l}\text { Stage 5: Social contract orientation (varying personal values are } \\
\text { recognised but are mediated by social agreement and a democratic } \\
\text { approach in society as a whole; the law is respected but is subject to } \\
\text { change if it is not just) }\end{array}$ \\
\hline & $\begin{array}{l}\text { Stage 6: Universal ethical principle orientation (right decisions/actions } \\
\text { are defined by ethical principles that are universal and consistent, which } \\
\text { emphasise justice, reciprocity, rights and respect for human dignity in } \\
\text { society) }\end{array}$ \\
\hline
\end{tabular}

Source: Kohlberg, L., Levine, C. and Hewer, A. 1983, Moral Stages: A Current Formulation and A Response to Critics, Karger, Basel.

Kohlberg's model also appears to provide evidence of the ways in which people from different cultures make decisions, ${ }^{28}$ with different cultures passing through the stages of the model differently, usually in the same order, but not

25 Kohlberg, L. 1971, 'Stages of moral development as a basis for moral education', in C. M. Beck, B. S. Crittenden and E. V. Sullivan (eds), Moral Education: Interdisciplinary Approaches, University of Toronto Press, Toronto, pp. 23-92; and Kohlberg, L. 1981, The Philosophy of Moral Development: Moral Stages and the Idea of Justice, Harper \& Row, San Francisco; and Kohlberg, L., Levine, C. and Hewer, A. 1983, Moral Stages: A Current Formulation and A Response to Critics, Karger, Basel.

26 Kohlberg et al., op. cit., p. 6.

27 Kohlberg, L. and Gilligan, C. 1971, 'The adolescent as a philosopher: the discovery of the self in a postconventional world', Daedalus, p. $1051 \mathrm{ff}$.

28 Harkness, S., Pope Edwards, C. and Super, C. M. 1981, 'Social roles and moral reasoning: a case study in a rural African community', Developmental Psychology, vol. 17, part 5, pp. 595-603. 
always to the same end. This means that people in any given culture only need to achieve the level of reasoning that is necessary for their culture to operate effectively. ${ }^{29}$ Nevertheless, even when different cultures have different attitudes to an issue, they will express the same reasoning methods when coming to their differing conclusions. I would suggest that individuals and groups may operate at several levels simultaneously, depending on the multiple contexts they are operating in at any one time (home and work, friends and work, friends and home, and so on), and this may be a mechanism by which scientists manage any clash between their private morals and public ethics. In addition, I would suggest that although we may like to think we are all operating professionally in Kohlberg's 'Stage 6', we are probably not, or at least, not all the time and in all circumstances.

Kohlberg's work has been subject to criticism, including that his work is culturally biased. Simpson ${ }^{30}$ said that Kohlberg's stage model is essentially based on the Western philosophical tradition and that it is inappropriate to apply it to non-Western cultures without adequate reflection on their different moral outlooks; however, the model appears to remain a useful indicator of the development of moral reasoning per se, and I would suggest that as long as cultural variations are effectively and appropriately considered as variables when applying the model, it retains useful credibility.

We must also consider the psychological effects or outcomes of our personal cultural upbringing. A range of cultural factors may be explained by psychology as well as by anthropology and the social sciences. Characteristics of cognition, motivation and social interaction may answer questions about the origins and development of any culture, and subsequently those subject to the influences of a culture. For example, a society that values the rights of the individual will produce people who think differently about any given scenario to people who originate from a society that does not place the rights of the individual high on the social agenda. Likewise, cultural views on gender, equality, age, family structure, education, work, marriage, religion and science all influence us heavily as we grow up, embedding within us a standard of 'normality' by which we measure the rest of the world. This is the basis of some of the criticism of Kohlberg's stage model. It is probably only when we leave the confines of our own cultural context that we are challenged to focus on our own reactions to 'the others', and have to negotiate ways forward that enable us to coexist in a mutually acceptable way. This can, of course, include the transition from the private, domestic sphere to the professional, public sphere.

29 Ibid.

30 Simpson, E. L. 1974, 'Moral development research', Human Development, vol. 17, pp. 81-106. 


\section{Private morals, public ethics and dual-use/ biosecurity education}

When considering the biosecurity and dual-use dilemma therefore, we need to recognise that life scientists bring to their existing professional ethical perspectives a range of prior moral perspectives that influence the ways in which their professional ethical views and behaviour develop. There may even be multiple levels of prior professional ethics and norms involved in this equation. A practising scientist may have been required to adhere to different norms in different laboratories and workplaces; ${ }^{31} \mathrm{~s} /$ he may have been required in one place to prioritise safety over economics, but then be pressured to reverse this elsewhere; leaders in one workplace may resist post-qualification research training to the detriment of the team, whereas leaders in another may promote such training - the scientist finds himself in the new workplace with his 'old' norm of resistance to training in place, and as a result, he finds he is viewed by the new team as backward and unwilling to change, unless of course he manages to revise his view on training. A number of cultural expressions may affect this process, and although as scientists, individuals may all tend to publicly express similar value sets, as scientists, they will be modified by the underlying culturally mediated values of their earlier life experiences. This will occur at both the individual and the group levels.

In order to understand this more fully, it is useful to consider why certain behaviours and attitudes develop. Private morality, according to work by Kohlberg, Wilson, Piaget, Catchpoole and others (above), involves characteristics of altruism, care, empathy and a sense of justice. Krebs and Janicki ${ }^{32}$ suggested that the way in which these are prioritised and acted on by a given group may be an adaptive mechanism, with people choosing the adaptation that best helps them to tackle given cultural problems and manage their own responses in such a way as to enable them to work. For example, scientists' views may conflict with the institutional views of the workplace in which they operate, but in order to keep their position and retain a reasonable lifestyle, they have the choice to either conform or be released from their position, perhaps with other penalties as well as the commensurate economic ones. There is arguably a tendency to overlook such cultural pressures and to insufficiently recognise the forces acting on scientists. An example of this may be seen in a situation that has been recognised under the Biological Weapons Convention (BWC): sometimes even well-intentioned international prohibition regimes can lead to confusing situations. The BWC prohibition norm's allowance for biotechnology research carried out for peaceful purposes has actually enabled a number of countries

31 See, for example, Bezuidenhout, Chapter 17 in this volume.

32 Krebs and Janicki, op. cit. 
to 'cloak their biological weapons programmes within seemingly legitimate facilities'. ${ }^{33}$ Scientists working in such conditions are faced with the need to juggle their private values and professional ethics in order to reach a state of equilibrium in which they can continue to work with the least possible stress and dissonance to them personally. ${ }^{34}$ This example offers a partial illustration and explanation of the different 'ethical' values and behaviours that we see apparently exhibited around the world today-in both developing and developed countries. 'Cultures' (national, political, ethnic and religious, in some cases) prioritise the values that enable them to best tackle the challenges they face, and at the micro-level, the individuals involved in these circumstances have to prioritise and compromise their own values within these contexts in order to survive. Martin wrote an excellent commentary on this, focusing on those workers who chose not to compromise their own moral and ethical values. ${ }^{35}$ I will return to this later.

So how do we draw together common ethical values from such disparate moral backgrounds within the context of the risks of the dual use of scientific activity? It may be argued that scientists already share a common culture, but Crandall and Schaller ${ }^{36}$ have highlighted professional/personal value clashes even within (and between) scientific cultures. They suggested that most scientists publicly state that they hold to an explicit set of values including a commitment to sharing universal truths, to sharing data with colleagues, to being disinterested in the sense of being non-judgmental and open to whatever the evidence suggests, and to a sceptical outlook that distrusts anything not supported by empirical data and observation. They also found, however, that a hidden agenda is apparent in the work of most scientists, which clashes with the explicit values of the scientific method. They suggested that in order to survive in the competitive world of science, scientists must employ a set of hidden values, including

33 Atlas, R. and Somerville, M. 2007, 'Life sciences or death sciences: tipping the balance towards life with ethics, codes and laws', in B. Rappert and C. McLeish (eds), A Web of Prevention: Biological Weapons, Life Sciences and the Governance of Research, Earthscan, London, pp. 15-33.

34 See the examples of 'Experiments of concern' given in the Fink Report, which states that review of research activity by the scientific community would be necessary if it involves (amongst other processes) demonstrating: how to render a vaccine ineffective; how to enhance resistance to antibiotics; or how to alter the host range of a pathogen. All of these activities could be legitimate elements of peaceful research, but who on a team engaged in such work is likely to raise any alarm if funding for the research and the team could be put at risk? See National Research Council 2004, Biotechnology in An Age of Terrorism, [Fink Report], The National Academies Press, Washington, DC, <http://www.nap.edu/catalog/10827.html $>$. See also the discussion of the ethical implications of publishing the reconstruction of the $1918 \mathrm{flu}$ virus when it was published in 2005. See Tumpey, T. L., Basler, C., Aguilar, P., Zeng, H., Solorzano, A., Swayne, D., Cox, N., Katz, J., Taubenberger, J., Palese, P. and Garcia-Sastre, A. 2005, 'Characterization of the reconstructed 1918 Spanish influenza pandemic virus', Science, 7 October, pp. 77-80. This paper was accompanied by an editorial in Science discussing the decision to publish the research, bearing in mind concerns about the risks of misuse of it.

35 Martin, B. 2007, 'Whistleblowers: risks and skills', in Rappert and McLeish, op. cit., pp. 35-47.

36 Crandall, C. S. and Schaller, M. 2004, 'Scientists and science: how individual goals shape collective norms', in Schaller and Crandall, op. cit., pp. 201-24. 
resistance to new ideas that challenge the status quo, the selective forgetting of data that contradict personal views, favouring of work supporting their own views and a generally conservative approach to their practice. Conflicts between the personal and professional value sets will obviously arise here.

This conflict may be explained psychologically by cognitive dissonance theory, ${ }^{37}$ which describes how, in situations in which an individual's behaviour or beliefs must conflict with beliefs that are integral to his or her self-identity (for example, when being asked to professionally prioritise a value that is not equally prioritised in his private value set), a conflict will arise. This conflict is referred to as cognitive dissonance. In order to resolve this dissonance, the individual can either leave the situation that presents the source of the conflict (in this case, the professional role) or reduce his attachment to the private value that is being challenged or compromised. If he does the latter then he may ease the conflict further by emphasising the positive aspects of the professional value that is challenging him. Cognitive dissonance is clearly an important factor in the decision-making process.

Three key psychological strategies are commonly used to alleviate cognitive dissonance. The individual may decide to seek more supportive beliefs or ideals that could outweigh the dissonance; in essence, this may mean 'masking' or suppressing the conflicting value and his response to it. This would, in turn, potentially cause longer-term psychological stresses. The individual may convince himself that the challenging belief is not really important, and can therefore be ignored or at least given less priority. He may also begin to manipulate or moderate the belief that is challenging him and seek to bring it more into line with his other beliefs and action patterns. These strategies involve rationalisation: the tendency to develop their own explanations as to why they have made their choices in relation to the challenging belief or action.

Festinger's cognitive dissonance theory has not been without its detractors. Bem $^{38}$ suggested that individuals' attitudes may be changed by self-observation of their own behaviours (rather than by any response to feelings of discomfort in a challenging situation), followed by consideration of what attitudes caused those behaviours, thus producing emotional responses. For some time it was considered that cognitive dissonance and self-perception theories were in competition; however, work by Fazio et al. ${ }^{39}$ identified attitude-congruent

37 See Festinger, L. 1957, A Theory of Cognitive Dissonance, Row \& Peterson, Evanston, Ill.; and Festinger, L. and Carlsmith, J. M. 1959, 'Cognitive consequences of forced compliance', Journal of Abnormal and Social Psychology, vol. 58, pp. 203-10.

38 Bem, D. J. 1967, 'Self-perception: an alternative interpretation of cognitive dissonance phenomena', Psychological Review, vol. 74, part 3, pp. 183-200; and Bem, D. J. 1972, 'Self-perception theory', in L. Berkowitz (ed.), Advances in Experimental Social Psychology, Academic Press, New York, pp. 1-62.

39 Fazio, R. H, Zanna, M. P. and Cooper, J. 1977, 'Dissonance and self-perception: an integrative view of each theory's proper domain of application', Journal of Experimental Social Psychology, vol. 13, part 5, pp. 464-79. 
behaviour and attitude-discrepant behaviour, with self-perception theory explaining the former and cognitive dissonance theory explaining the latter. Attitude-congruent behaviour was defined as any position within an individual's scope of acceptable behaviour and attitude-discrepant as any position within an individual's scope of rejected behaviour.

\section{The conflicted scientist: An example}

Now that we have considered biological and psychological explanations of moral development, let's look at the scientist we mentioned at the start of the chapter. This hypothetical, recently graduated biochemist was appointed to his junior post as a research assistant on a team in a commercial organisation developing vaccines to counter an emerging tropical disease.

Let's imagine that his team leader and his employers prioritise economic and scientific advantages over what they perceive to be the requirements of biosecurity; indeed, the organisation believes it is already accommodating biosecurity concerns through its biosafety policy. In as much as it has been addressed at all, biosecurity as a concept is generally considered to be irrelevant in the organisation's laboratories because the management does not believe that their work presents any biosecurity risk. Moreover, it is vital that this organisation maintains scientific and economic leads over its competitors.

Our scientist has been brought up at home to believe that it is socially necessary to abide by 'the rules' in life, so that everyone can live together in the community in some sort of respectful harmony. At school and at university, he modified this 'necessity' into a more flexible 'suggestion', meaning that he continued to abide by the rules (which he is quite good at doing, at least in as much as it benefits him), but felt able to ignore some as it suited him. In his childhood, he learned that respect for the quality of life of others, as well as his own, is a key value, and that he should always do his best to ensure the safety and wellbeing of others. He learned respect for his elders, politeness and the need to recognise his own position in the 'food chain' both socially and at home. At work as an adult, he believes that his leaders adhere completely to what is often known as 'the scientific method' (not an official term, but one that implies a commitment to empiricism, objectivity, truth, openness and so on; whether one accepts this or not is an interesting discussion in itself), as he believes he has seen them do so regularly. He generally accepts the values that his scientific leaders pass on to him both consciously and unconsciously. He has somehow forgotten the one or two instances in which he noticed his leaders taking shortcuts in an experiment and ever so slightly exaggerating a finding in a paper. Seeing himself 
as a qualified and employed scientist, his priorities are twofold: accepting and promoting the 'scientific method' as an independent, value-free and objective concept, and making sure he gets on well with his workmates and bosses.

He can see that his organisation's new vaccine has considerable economic potential as well as humanitarian value; however, he is unexpectedly challenged by the need to manage his response to some new values - in this case, a new version of the biosecurity norm - which have been presented to him through an international report ${ }^{40}$ he has just read. He wishes to persuade his colleagues of the new perspective that he has recognised because he is so persuaded by the argument that he has prioritised this 'new' ethical approach at a high position in his own professional value set. He is concerned that one or more of the processes involved in the vaccine research and development could be used against human populations if they were to be used maliciously. He sees this very clearly once he has thought about it, and is concerned that no-one at work has considered this before. How can he proceed?

He tries to tell his colleagues about his concerns. One or two of them agree that there may be some theoretical risk, but generally take the view that it will never happen' and tell him that he should forget about it. Some point out to him that this new process will generate a lot of money for the organisation (and longterm employment) and he should not raise problems with it. He tries to forget his concerns, but as he continues to work on the new process, he sees more and more chances for it to be misused. Other researchers from different branches of the organisation have had access to the laboratories during the work, and no confidentiality mechanisms were in place that would have prevented them from seeing the work, so the processes could already be repeated at other sites.

Our scientist's research team leader is planning to publish the work, albeit not in full, so as to protect the organisation's economic advantage. Even so, key processes and outcomes can be relatively easily worked out by anyone with a basic knowledge of genetics and vaccine science from what is to be published. In order to advance his position further in the discipline, his team leader is also going to give some more detail in an international conference podium presentation, where he will take questions and presumably give some answers. Our scientist goes to see the team leader to ask him if it would be possible to restrict the amount of information given out in the publication and at the conference, as he has concerns about security and what could happen if the information fell into the 'wrong hands' (delegations from certain countries with security problems will be present). His team leader is shocked and annoyed at the suggestion that he could possibly be involved in work that could be used to make, in effect, a biological weapon. He challenges our scientist to show him

40 For example, National Research Council, op. cit. 
what is wrong with the work, and goes on to say that he cannot be responsible for what someone else may do with 'his' work. Our scientist is not sufficiently up to speed with all the possible ways in which the work may be misused, but he suggests that certain potential outcomes of the research could be used against the interests of society. He finds it difficult to understand that his colleagues and team leader cannot see the potential problems that may arise from the team's work on interfering with the susceptibility of organisms to vaccines; they do not seem to be concerned that it could be used against human communities. The team leader then falls back on the argument of scientific freedom and the duty of the scientist to share and to replicate work with other scientists. Moreover, he also points out that the research is going to generate a major income stream for the organisation. He suggests to our scientist that he might wish to consider his junior position on the team, and points out that contracts will soon be up for renewal. Over the next few weeks, the team leader begins to give more work to other colleagues on the team and less to our scientist, who does not receive an invitation to the conference at which the leader is to speak.

Our scientist manages to find a friend who is quite senior at another workplace, with whom he shares his concerns in a general way. This new friend suggests that he could think about what it is about his own values that is causing him so much stress in this situation. He has another friend, who is not a scientist, who says that he should ignore the stress and what others say, and simply focus on himself and what he can do to change himself in order to manage better at work. Our scientist is now in an ethically challenging situation and does not know which way to turn. What should he do?

We can review our scientist's position using the concepts that we have been looking at in this chapter. His upbringing has given him a family-based, culturally derived value set (a bio-cultural mechanism) that encourages him to abide by the rules in order to maintain his social position and to gain advancement socially as he 'fits in' with his 'tribes' both at home and at work (Wilson's theory). He has grown up with this approach, which has worked so far, but if he has to challenge it beyond certain narrow limits, he feels emotionally stressed (Griffiths' and Izard's theories). He is aware that it is necessary to balance competing values and tries his best through life to manage the periodic clashes between the need to fit in and the need to maintain his own values (the theories of Sahlins, Gould and Lewontin on cultural drivers overcoming genetic drivers). He feels that it is possible to manage this sort of balance by everyone 'giving and taking' in order for everyone's needs and values to be accommodated (Trivers' reciprocal altruism). He is aware that some people are manipulators and will take when appearing to give, but as long as it all 'balances out' he is happy and assumes that everyone else is as well (Moore's criticism of Trivers, and the work of Mauss on gift-giving as a means to self-promotion). He is even of the mind, at times, 
that Dawkins' ideas on genes as drivers can be related to humans in the sense of 'every man for himself', although he does not like this view of life, as it seems uncaring and inhumane.

He has a number of options for dealing with these questions (psycho-cultural mechanisms). He is vaguely aware that he manages the periodic clashes between his personal and professional value sets by balancing his unconscious feelings of guilt and shame for 'doing wrong' if and when he steps out of line in the family or at work (Williamson's theory). His mechanisms for managing these emotional reactions are those described by Krebs and Janicki- he always manages, usually unconsciously, to use one of their four ways to make sure he can operate in 'the right way' in any given situation. He is, unconsciously, at different stages of Kohlberg's model depending on which context he is operating in at any given time-for example, at home, at work or at play.

Now that he has been confronted with the challenge at work that I have described above, he is faced with a situation of cognitive dissonance. In order to remain at work and to flourish in the way he wishes to professionally, he must now either conform to the prevailing view at work by giving up his concerns (or at least stop talking about them) or choose to leave and seek work elsewhere. As a junior member of the team, he does not think he is in a position to influence the team himself. If he were higher up the 'food chain', he may feel that this is a third option.

Our scientist now has four options to mitigate his cognitive dissonance at work, thereby relieving himself of any sense of ethical responsibility about the possible outcomes of the scientific activity of his organisation. First, he may choose to look for some other beliefs that will help him to mask the dissonance so he can pretend it does not exist; he could do this by saying to himself that his actions alone will have no effect in the 'big picture' as he is only a junior researcher: 'what do I know?' Second, he may decide to go along with his colleagues and persuade himself on some level that 'it will never happen'; he could do this by actively deciding that he is worrying over nothing - he may be the only person who has seen the potential problems, so maybe he is blowing it all out of proportion and he is 'worrying about nothing'. Third, he may try to manipulate, in his head, the challenges that the dissonance is causing, so that the views of his leader and colleagues do not cause him so much difficulty; he may do this by reassessing the value that he places on the views of his colleagues and leaders, deciding that their views are not as important to him as he previously thought. Fourth, he may choose to be a 'whistleblower' and speak publicly in some way about his concerns.

The first three approaches involve our scientist in a process of rationalisation whereby he will be able to invent and justify his own explanation as to how 
he has reached his eventual position of relative ethical comfort (or discomfort). Unfortunately, all these actions are likely to lead to further stress, which may debilitate him in the future. In the first instance, he is effectively degrading his own value in the team as a scientist and as an individual. In the second, he is subduing his own intelligence and ignoring what his own values and intellect are telling him. In the third, he is downgrading the value of those to whom he naturally looks for learning. All of these rationalisations ultimately mean compromise of his personal and professional values and are highly likely to result in further dissonance.

In terms of self-perception theory, all three strategies will simply move him to various stages along the continuum of attitude-congruent (acceptable) and attitude-discrepant (unacceptable) behaviour. If he makes himself comfortable at one point, this means that he will thereby throw up a further dissonance that requires another relocation on the continuum. This may progress to such an extent, raising more and more stress, that our scientist may feel that he is in an impossible situation if he is unable to convince his colleagues and leaders to take his concerns about the research seriously and to act on them.

The fourth approach - to become a whistleblower-is, unfortunately, not a stress-free option, even though it may assuage his moral and ethical concerns. Our scientist may well 'blow the whistle' on the research, and be the cause of it being abandoned or amended by his organisation. So far so good - he may have prevented a possible biosecurity threat from translating into an unwelcome action; however, in the process of doing this, if we read Brian Martin's work on whistleblowing, ${ }^{41}$ we find that he is highly likely to be ostracised by his workmates, sidelined (at best) in the organisation and, more likely, fired from his post as a result. If not fired, he may find that his contract is not renewed as the organisation is 'restructured'. Either way, he now has no job, no references and little hope of continuing to work in the field he had chosen to spend his life in. This prevents or seriously delays him buying his first house, starting a family and advancing up the career ladder. Maybe he should have kept his mouth shut after all?

\section{A way forward: Memes and norms}

Given that modern-day whistleblowing is such a dangerous option for the individual to take, and given also that we accept the concept of biosecurity risks being inherent in biotechnology research, it seems that we need to find a way forward that reduces the necessity for whistleblowing to take place and

41 Martin, op. cit. 
reduces the risk of biosecurity lapses occurring. One such way is to develop and foster a new norm of biosecurity; this would become, in time, a part of everyday scientific practice, just as the biosafety norm is hopefully embedded in daily activities.

This is best considered in the context of the ways in which scientists carry out their daily activities and approach potential challenges in their work. We have seen earlier in this chapter that there are two possible psychological mechanisms - bio-cultural and psycho-cultural - that may be usefully pursued further when attempting to identify, understand and predict the changing perspectives of scientists when faced with the challenges of biosecurity in their professional and personal lives. We should therefore consider these potential explanations in the derivation and development of value sets or norms when developing a new ethic of biosecurity and dual use. What we are faced with is, essentially, a relativist scenario not only between the differing values held by different people in regard to specific concepts, but also in the differing values held by individuals themselves in terms of specific concepts through conflict between their private moral values and their public ethical values.

Now that we have seen the challenges faced by our hypothetical challenged scientist (albeit supported by real-life examples in Brian Martin's work), let's look at how cultural ideals and values can be transmitted effectively, thus, hopefully, avoiding or reducing the chances of his situation being repeated in real life.

Norms may be defined as formal or informal rules that govern what is acceptable in terms of behaviours, attitudes, beliefs and values within a group or culture. They may be explicitly stated or implicitly approved by the majority; they may lead to warnings or reproach for those transgressing minor normative rules, or to more severe punishment for those guilty of the transgression of norms considered to be of great consequence. Norms develop over time, and are subject to a range of cultural influences. They are often closely tied to religious and social forces, and are commonly associated with group or cultural identity. Once this cultural identification element takes hold, it may be particularly difficult to dislodge or change a norm. Considering that such norms are usually part of our childhood development and therefore our moral learning process, we can see how they may challenge later professional ethical values that may clash with them. So how do we develop and implement a new norm? Maybe it is better to start with a smaller task and look at what Dawkins refers to as memes, which may be referred to as 'infant norms', for want of a better term. 
Memes $^{42}$ are units of cultural transmission that may be skills, knowledge, beliefs, attitudes, behaviours or values. They are spread through observation and social learning ${ }^{43}$ and have been called 'cultural software' ${ }^{44}$ that may be passed on as they are or in modified forms. Dawkins has, in the past, cited the fashion for wearing a baseball cap back-to-front as an example of a meme that has spread through certain sections of society. One could argue that a well-entrenched meme becomes, in effect, a new norm, if it lasts long enough. Crucially, unlike genes and norms, which can take long periods to change, memes can, apparently, change very quickly. It may follow then that ethical attitudes, knowledge and characteristics could also be transmitted as memes, which, in passing from one person to another, will change slightly with each transmission, allowing development and swift cultural change to occur:

The power of human reason made possible in part by the memes we possess, is also the power to mutate those memes and create something new from something old. We are not simply inheritors of a zealously guarded patrimony but entrepreneurial products of a new cultural software which will help constitute future generations of human beings. ${ }^{45}$

In order for old memes to be transmuted into new memes, however, there must be a dominant host culture that allows change to take place.

In order to enfranchise and empower all people there needs to be a mutual exchange between equals. If some individuals or groups are marginalised or excluded for any reason, be it at the political, legal, social or economic levels, there is no basis for trust, mutual respect and cooperation. ${ }^{46}$

This is clearly the level at which we need to operate when developing a new norm of biosecurity as it is embedded in the responsible conduct of science. In any moves to take on board shared common ethical values, it is vital that we do as much as possible to support all actors in the biotechnology field so that no-one is left behind and marginalised. Such help does not need to be financial, although it could be, at least in part. Help could be provided in the form of intellectual, educational, training or other relevant forms of support as well. Once a norm has become established, recognised and shared among growing numbers within a community, it is important that we define appropriate penalties to be faced by those breaking the norm. Next, we need to agree on the implementation of those penalties; without imposed penalties, a norm, by its very nature, is effectively

42 Dawkins, op. cit.

43 Catchpoole, op. cit., p. 77.

44 Balkin, J. M. 1998, Cultural Software: A Theory of Ideology, Yale University Press, New Haven, Conn., and London, p. 43, cited in ibid., p. 265.

45 Ibid.

46 Catchpoole, op. cit., p. 267. 
toothless. In today's world, it may be argued that the economic penalty is the one of greatest effect; however, penalties need not be just economic - but that is another argument for another day.

Let's now consider the education route as a norm developer. Education is itself a memes transmitter. We absorb new memes through the values set by those who pass the new values on to us. Over time, new memes can become new, deep-rooted norms. Social norms (such as the baseball cap) may start as memes, developing into expectations of behaviour, then into controls that regulate behaviour and identity (the baseball cap again). Philosophical norms imply some obligation or duty, carrying threatened or real sanctions if they are broken. There is cultural pressure to abide within the norm, so culture provides a setting in which the norm may survive and develop.

Ethics and ethical attitudes may be passed on as memes (quick-changing, initially superficial cultural artefacts) and then develop over time into norms (more deep-rooted values and attitudes within a culture). Ethics, as norms, can be implicit or explicit. They can vary from group to group and place to place and can change over time. It is this capacity to change that we must address in order to develop a new ethics of biosecurity so that it becomes a dominant scientific norm. The biosafety norm is based on the principle of containment and safe management of harmful biological agents, but in such a way as to allow ongoing scientific practice; the biosecurity norm needs to be built on the principle of the containment and safe management of biological knowledge and processes, also allowing ongoing scientific practice. Just as the biosafety norm (when implemented properly) draws a line in the sand over which practice cannot step, so must the biosecurity norm.

So how may we develop research ethics as memes-into-norms and persuade others to sign up to them in the biosecurity context? This would mean taking a norm of, say, 'no harm', and defining it in practical ways in order to teach the principle. Catchpoole believes that new norms can be taught and developed as memes. She suggests that education can choose which memes to transmit and which it will not. ${ }^{47}$ Educational transmission of a commonly held value, such as care for others, could be 'inserted' as a norm as part of the building of a multicultural ethic of biosecurity, with a common value set, around it:

Having care for one another and our world involves finding a balance between the needs of self, close others and global others in ways that respect basic human rights and yet which seek to encourage more than a minimalist commitment to having care for one another ... By delineating the nature of care itself and recognising the ubiquitous nature of power 
within relationships, an extended ethic of care provides a set of transcultural memes for both guiding and evaluating the development of the ethical form of life in the private and public spheres. ${ }^{48}$

The memes of ethics could therefore be taught and learned as a form of cultural transmission in a multicultural context if they are presented from the perspective of a commonly held value such as care for others, which few cultures would dispute. ${ }^{49}$ At the same time, we need, however, to recognise that a range of cultural pressures may be brought to bear on the implementation of a 'no harm' or 'care for others' value. It is one thing to state a belief in 'do no harm to others' publicly, but at the same time, be driven by a more pressing value to actually prepare to do the opposite - we only need to look at those countries in violation of the BWC with their 'peaceful purposes' cloak hiding offensive weapons programs to see real-life cases in action. This prioritisation of pressures is to be the subject of further research. ${ }^{50}$ One could argue that the norm of 'no harm' is so routinely violated in science (for example, in the use of animals in product testing) that it is diminished as an argument and is no longer worth pursuing or developing in practice; however, this in itself is an ethical debate: we either accept the norm of 'no harm' as being something to aspire to or give in to an anarchic world in which 'care for the other' no longer has a place worth arguing for. I would suggest that it is 'inside' the norm of 'no harm' that much future research is required. We can readily see that many individuals and groups apply this norm differently, simply by the way in which they define who is to be actually protected from harm, in what circumstances and why. This is the area in which we seem to make our moral and ethical judgments based on culturally appropriate norms with which we face everyday life.

\section{Conclusions}

This chapter has shown that we need to appreciate the variety of private moral backgrounds of individual scientists as we seek to identify common values with which to form a new norm of biosecurity within the public culture of ethical science.

It is probable that there is a biological foundation underpinning our moral development from infancy into adulthood. On top of this genetic and physiological framework, we can identify a range of psychological processes that further

\footnotetext{
48 Ibid., p. 47.

49 Ibid., p. 186.

50 Further culture-based research is being planned by Judi Sture and Masamichi Minehata of Bradford Disarmament Research Centre, looking at how scientists and educators prioritise and manage pressures in their everyday work.
} 
develop within us an increased capacity for empathy and consideration of the rights of others. Some of these processes have been identified and categorised by Kohlberg, Hoffman and others. An increasing body of work has shown that psychology is a powerful factor in the development of culture, and that it is possible to understand the nature and growth of cultures and cultural changes through the lens of psychology. This is an area ripe for further investigation in the biosecurity context.

Each individual scientist engaged in work or research that has or may have potential for misuse is faced with a moral-ethical dilemma of his own. His private moral value set(s) may come into conflict with his publicly required professional value set(s). Because they are culturally derived and embedded, private moral values can be difficult to change, as they are usually driven or controlled by one of five expressions of culture - social organisation, economics, technology, religion or language - all of which are interlocking and may be hard to shift (these expressions of culture are commonly used by archaeologists in understanding culture). ${ }^{51}$ We need to identify the key drivers from among these five expressions that influence the private morality that scientists bring to their professional ethics, in order to challenge them and move forward to a common value set. In addition, we need to recognise how these drivers also inform public ethics in the workplace. By considering a number of existing theories such as cognitive dissonance and self-perception, against a biological background of genetic and evolutionary tendencies to altruism, emotional reaction or selfinterest, it may be possible to delve into the processes that give rise to the professional ethical value set(s) of scientists in any given cultural setting and that inform their prioritisation of each of the five expressions of culture.

Against the background of a call for increasing awareness of dual-use issues, ${ }^{52}$ we may consider the following fields of activity and inquiry in order to move forward. First, we need to help scientists recognise their own value sets and identify how they may clash with both the values of the science they practice and the need to protect against the risk of dual use. Second, we need to review our institutional organisations and look for hidden curricula (confounding values that compete implicitly with required values) in science at governance and teaching levels that may be impeding the search for and implementation of a common value set in biosecurity and dual use. Third, in our aim to embed a new ethics of biosecurity and dual use within the culture of life sciences, we need to consider a range of psychological drivers that influence others and

51 See Renfrew, C. and Bahn, P. 1991, Archaeology: Theories, Methods and Practice, Thames \& Hudson, London.

52 United Nations 2008, BWC/MSP/2008/5, p. 6. 
ourselves. Fourth, we need to look out for threats or undue influence from the five archaeological expressions of culture, as these may exert overt or covert pressure on scientists.

Finally, by identifying even a single commonly held value, such as care for others, it may be possible to start laying the foundations of a new value set that will underpin our efforts in building a sustainable capacity in biosecurity in the life sciences. 